\title{
Architectural Space and Psychological Feelings
}

\author{
Zhao Ruoxi \\ China Academy of Transportation Sciences, Beijing 100029, China \\ 13810969041@163.com
}

Keywords: space; function; feeling; form

\begin{abstract}
Today, as the architectural design and development has becoming increasingly mature, the functions are no longer the principal contradictions of building, and on the other hand, the psychological feelings generated by building are not emphasized by the architect. Different buildings can generate different psychological feelings. Each building will generate different spaces, each building also consists of various spaces, and each space can give people different feeling. The psychological space of building has both important application value and great artistic value, which can not only help the architect to more systematically design the overall architectural space, but also help the building user to more comprehensively recognize the space. Today, with general emphasis on the architectural environment, the research and application development of architectural psychology and the realization of a harmonious and uniform relation between people and building can actively promote the architectural creation field.
\end{abstract}

\section{Architectural space affects the psychological feelings}

Buildings with various functions are important components of a city, and if roads are the blood vessels of city, buildings are like the flesh of the city. If there are people, there will definitely be buildings. A building is like a gigantic artistic work, which is everywhere in people's life. People's basic necessities of life require various buildings, such as business building, residence building and transportation building. Different types of buildings will trigger a series of psychological activities of people, such as feeling, cognition, memory, association and thinking.

Different styles will cause different feelings. For example, in Suzhou traditional garden of China, the natural elements are introduced as the spatial elements in the garden, which form rich spatial effects with the pavilions, hills, flowers and trees, and you will feel pleasant and happy at every part of the garden, which can make you completely relaxed. Another example is the Chinese temple, it is symmetrical, stable and generally discreet, full of the mystery that combines the heaven and earth, which is elegant and solemn with far-reaching conception, and it can instantly make you full of deep esteem.
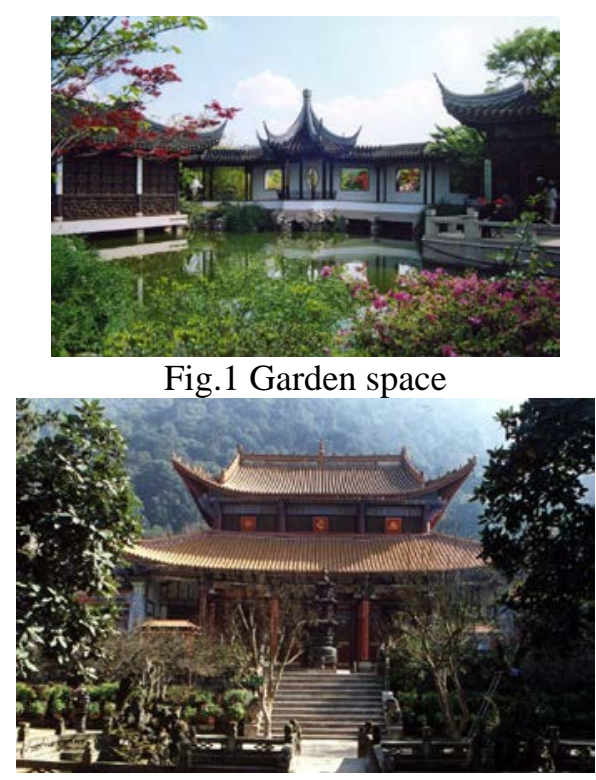

Fig.2 Temple architecture

Each building has certain functional space, and each function decides the form, size and quality 
of the space. Function is not the only requirement for space, and people's psychological feelings are also closely related to the architectural space. People's feeling toward object is generated through stimulation, which is the sense organ's reflection of the individual attribute of objective matter. On deep level, the position of various matters is decided by a series of human perceptual factors, and people can feel the stimulations brought by space through certain functions and sensations provided by the space.

Generally speaking, people can only experience the existence of space when staying in a certain space, and different architectural spaces could become quieter or more energetic due to the existence of human. Take the square space for example, people feel it is a square because it is wide open. This kind of feeling differs based on different perception objects, space service objects and utilization objects. As a person who lives in the city, if he comes to the rural area, he will feel unprecedented fresh, like returning to the nature; while for a farmer who has lived here for a long time, he wouldn't feel anything. With the same space, from different psychological perspectives, the architectural space will also trigger different feelings. Therefore, the architectural space is closely related to people's psychological feelings.

\section{Change of space affects the psychological change}

The space is infinite and shapeless, but it is also ubiquitous. All forms adhere to the space, which transform with the time and space. The space can be solid or virtual, which creates different psychological feelings through different forms. Different processing methods of location, form, texture and color can cause different spatial magnitudes perceived by your mind.

People's visual scanning order is generally up-down and left-right, the form of center point is the visual center, and so different perceptions of spatial magnitudes will be generated at different positions. In the plane space, the form at the upper part is lighter than at the lower part, or otherwise, it will leave people an impression of front heaviness. Different colors and textures can also generate different spatial magnitudes: the forms of low color transparency, low purity, cold color and simple texture can produce a receding feeling, which can make people feel quiet, and it shows profound and simple cultural deposits; the forms of high color transparency, high purity, warm color and rich texture can create a feeling of advance, boisterousness and prosperity, which can make people exited, it is also easy to remember, and it can also generate different front and back levels and form a sense of space. High buildings are magnificent and eye catching, while low buildings are steady.

On the aspect of form, compared to the form of the same size while with irregular profile, simple form feels smaller. For the directional form, a big space should be left along the direction, or otherwise, it will make you feel crowded. The wholeness of form also affects the space psychology. For the forms with same intake in space, the form of irregular edge will make you feel spacious, and if the form is in the center, it will make you feel crowded.

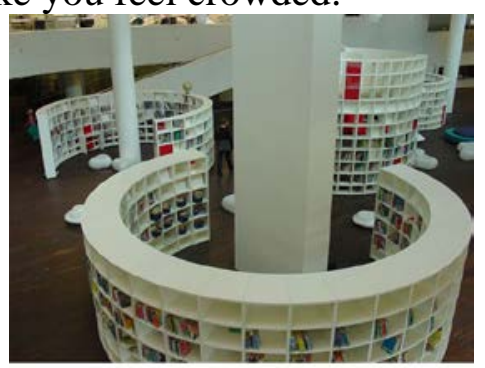

Fig.3 Curve space form

Different types of architectural space can bring different psychological feelings to people, including the sense of security, comfort, affinity and distance. The safety issue should be considered during architectural design, and the space without molimen cannot create a sense of security. In the meantime, the space distance is also one of the elements for the sense of security, such as the space, personal, social and public distance, the distance directly affects the size of space, and you won't feel safe if the space is too big or too small. The sense of comfort is the basic standard to measure the building quality, and the rationality of the color and void-solid matching and comparison of 
architectural space will directly affect people's feeling of the architectural space. Different architectural techniques can generate different psychological feelings. For example, the mysterious religious building requires a sense of distance, while the kindergarten building should generate a sense of affinity. By reducing the space aspect ratio and intensifying the space sense of closure, the sense of affinity of the space can be increased; conversely, the sense of distance can be increased.

\section{Conclusion}

At present, most big cities have a huge population, in addition to work, people are having less and less communication, and it is the desire of many people to build a proper architectural space within difference spaces. With the continuous progress and improvement of architectural technology and the gradual promotion of green building and intelligent building, the relation between the architectural space and people's psychology should be gradually emphasized, which can not only make the space artistic, but also enrich new contents. The artistic feature of space decides the design and construction level of building. The space art is constrained by people's psychology, which also affects people's psychology, and these two aspects depend on and coexist with each other. The high-quality architectural result must have a great artistic space, and this kind of artistic space can definitely satisfy people's requirement for space art. These three aspects have naturally become a complicated and closely related integrity, and this kind of understanding can both help the designer to design the space art and help the viewers to appreciate and feel the artistic space.

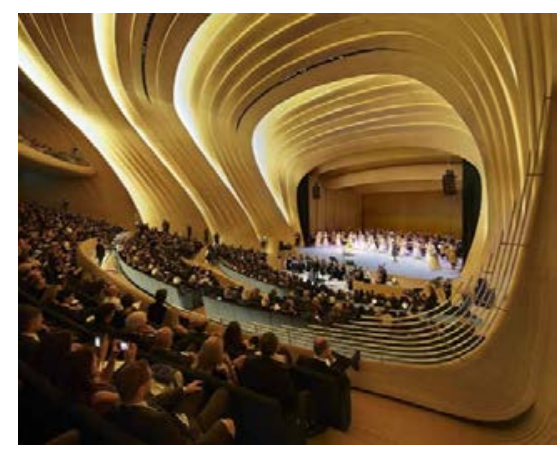

Fig.4 Artistic space

The relation between the design of architectural space and people's psychology is complicated and subtle, which are closely related to and mutually impact each other. The form, magnitude, color and void-solid can both reflect different expressions of building. Through exaggeration, implication and blurring, different characteristics of the building are expressed, which can create different psychological feelings to people. The abstract "feeling" is transformed to specific "object", the abstract graph is transformed to specific architectural form, and it should meet the artistic aesthetics, people's emotion and the user's satisfaction.

\section{References:}

[1]. Architectural Space Combination, Peng Yigang, 2005;

[2]. Graphic Analysis of Environment Design, Jing Qimin, Zhang Li'an, 2009;

[3]. Introduction of Psychology, Xu Liancang et al., 1988.

[4]. Cao Canjing., Psychological behavior and architectural space design., Science and technology information, 2009 (11) 317105

[5]. Chen Bingzhi Wang, Wang, Wu, Qing. Application of architectural psychology in architectural space design. Sichuan architectural science research, 2012 (5) 240-242.

[6]. He Zhixian. The application of environmental psychology in architectural design. Management engineers, 2013 (4) 35-37. 